\title{
PEMANFAATAN APLIKASI GOOGLE SEBAGAI MEDIA PEMBELAJARAN PADA MATA KULIAH PANCASILA
}

\author{
Iis Dewi Lestari \\ Program Studi Teknik Informatika, Universitas Indraprasta PGRI \\ Email: Iisdewi_lestari@yahoo.co.id
}

\begin{abstract}
Abstrak
Beragam media pembelajaran online menjadi pilihan yang harus dijalani oleh para pengajar di tengah pembelajaran online. Memilih media pembelajaran yang tepat perlu dengan cermat yang disesuaikan karakteristik dan kebutuhan mahasiswa dan dosen. Aplikasi Google menjadi banyak pilihan para pengajar dalam melakukan pembelajaran online. Dosen mata kuliah Pancasila di prodi Teknik Informatika menggunakan aplikasi Google dalam menunjang pembelajaran Pancasila. Tujuan penelitian ini adalah untuk mendeskripsikan penggunaan aplikasi Google dalam mata kuliah Pancasila dan untuk mengetahui kelebihan dan kekurangan dari aplikasi Google dalam pembelajaran online. Metode yang digunakan adalah kualitatif deskriptif. Subjek penelitian ini adalah mahasiswa dan dosen mata kuliah Pancasila prodi Teknik Informatika pada bulan September-Desember 2020. Teknik pengumpulan data adalah observasi, wawancara dan dokumentasi. Teknik analisis data yaitu reduksi data, penyajian data dan penarikan kesimpulan. Hasil penelitian ini adalah aplikasi Google sangat membantu pembelajaran online pada mata kuliah Pancasila dikarenakan melalui aplikasi Google, maka dosen dan mahasiswa dapat menggunakan Google meet untuk berdiskusi secara virtual, dapat mengumpulkan tugas melalui classroom serta daftar hadir melalui Google Formulir. Adapun kekurangan pada aplikasi Google yaitu tidak ada notifikasi tentang berapa banyak mahasiswa yang sudah mengunduh materi atau video serta hanya terbatas pada pemilik akun Google.
\end{abstract}

Kata Kunci : Aplikasi Google, Media Pembelajaran Online, Pancasila

\begin{abstract}
Various online learning media has become an option for lecturers during online learning. Choosing the right learning media needs to be taken carefully in accordance with the needs and the characters of students and lecturers. Google application has been chosen by many lecturers during online learning. Lecturers of Pancasila course in the Informatics Engineering study program use Google application to support Pancasila learning. The purpose of this study is to describe the use of the Google application in Pancasila course and to see the advantages and disadvantages of google application in online learning. The method used was descriptive qualitative. The subjects of this study were students and lecturers of Pancasila course in Informatics Engineering study program. The data techniques were observation, interview and documentation. Data analysis techniques were data reductions, data presentations and conclusions. The result of this research discovered that Google application was very helpful for online learning in Pancasila courses because through google application, lecturers and students were able to discuss virtually through Google Meet, collect assignments through Classrooms, and list attendance using Google Forms. The lack of Google application were there was no notification of how many students had downloaded material or videos, and it was only limited to the user of the Google account.
\end{abstract}

Key Words : Google Application, Online Media Learning, Pancasila

\section{PENDAHULUAN}

Pada masa pandemi Covid 19, pembelajaran beralih dari offline menjadi online. Tentunya hal ini membuat dosen sebagai tenaga pengajar perlu membuat sebuah inovasi dalam pengajaran online agar pembelajaran selama pandemi tetap berlangsung efektif serta mahasiswa dapat tercapai dalam tujuan pembelajaran. Untuk dapat menetapkan media pembelajaran yang tepat bagi mahasiswa dan dosen bukanlah hal yang mudah. Hal ini dikarenakan dibutuhkan pemahaman dan kesepakatan kedua belah pihak dalam 
menggunakan media pembelajaran yang disesuaikan dengan karakteristik dan kebutuhan mahasiswa. Media pembelajaran menurut Talizari dalam hasil penelitiannya menyatakan bahwa [1] media pembelajaran merupakan salah satu metode yang digunakan oleh guru untuk mengatasi permasalahan dalam kejenuhan dengan siswa pada saat pembelajaran di kelas, proses membagikan informasi yang dilakukan oleh guru serta sarana untuk memberikan materi dan pemahaman terkait pembelajaran. Media pembelajaran yang digunakan di tengah kemajuan teknologi dan informasi yaitu dibutuhkan sebuah perangkat lunak yang interaktif yang dapat menunjang dalam proses pembelajaran seperti aplikasi Google [2].

Berdasarkan hasil penelitian diketahui bahwa untuk mata kuliah Pendidikan Pancasila dan Kewarganegaraan sebagai mata kuliah umum sebaiknya dosen dapat memilih media pembelajaran yang kekinian disesuaikan dengan kondisi yang dibutuhkan oleh mahasiswa dan dosen di perguruan tinggi [3]. Dalam penelitiannya dikatakan bahwa perlunya pengembangan pembelajaran yang variatif, yang mencakup pendekatan kontekstual, konstruktivisme dan open-ended. Dari hasil penelitian tersebut, penulis melakukan optimalisasi dalam penggunaan media pembelajaran dengan menggunakan aplikasi Google. Melalui aplikasi Google maka cakupan pendekatan kontekstual dan konstruktivisme dapat dilakukan melalui aplikasi Google. Sehingga keterbaruan dari penelitian ini tentunya dapat mengoptimalkan aplikasi Google melalui Google Classroom, Google Formulir dan Google Meet. Peneliti pun menerapkan aplikasi Google tersebut sebagai media pembelajaran pada mata kuliah Pancasila. Kontribusi peneliti tentunya adalah memberikan gambaran dan saran bagi dosen-dosen mata kuliah Pancasila untuk dapat menggunakan aplikasi Google selama pembelajaran online agar dosen lebih inovatif dan mahasiswa pun mudah memahami materi dan termotivasi dalam mempelajari mata kuliah Pancasila.

Hal ini senada dengan yang disampaikan [4] yang menyatakan bahwa melalui melalui Google Formulir maka siswa akan termotivasi dalam pembelajaran online dengan menyediakan wadah tugas dalam bentuk formulir secara online. Tentunya dengan google formulir dapat meningkatkan profesionalisme pengajar agar dapat berinovasi dalam mengikuti perkembangan zaman di tengah pengajaran online.

Google Formulir merupakan template formulir yang dapat digunakan oleh pengguna untuk mendapatkan informasi, yang disimpan dalam Google Drive hanya dengan syarat pengguna cukup memiliki akun Google [5]. Hasil penelitian menunjukkan bahwa adanya pengaruh yang signifikan penggunaan Google Classroom terhadap motivasi belajar siswa [6]. Google Classroom merupakan aplikasi Learning Management System sebuah perangkat lunak untuk menyimpan dokumen, pelaporan dan kursus pendidikan [7].

Dari penelitian diketahui bahwa dosen harus memantapkan materi yang akan disampaikan melalui Google Classroom dan tugas yang diberikan kepada mahasiswa agar lebih maksimal [8]. Penggunaan media pembelajaran yang berbasis mobile dengan ketergantungan pada jaringan internet di era saat ini memiliki peran yang lebih besar untuk pengajar sebagai fasilitator dalam pembelajaran yang dapat dijadikan motivasi untuk siswa dalam pembelajaran. Mata kuliah Pancasila menjadi mata kuliah yang dijadikan pelengkap syarat kelulusan bagi mahasiswa di perguruan tinggi karena Pancasila merupakan mata kuliah yang 
wajib diambil oleh semua mahasiswa di semua jurusan [9]. Tentunya hal ini menjadi tantangan bagi tenaga pengajar dalam memberikan pengajaran yang terbaik di tengah pandemi dengan pembelajaran online. Dosen dituntut untuk mengenal, memahami dan menggunakan ragam media pembelajaran yang dapat menumbuhkan semangat mahasiswa agar adanya interaksi yang efektif dalam pembelajaran online. Penulis tertarik untuk menggunakan aplikasi Google dalam mata kuliah Pancasila di semester 1 dan 5 yang memiliki jumlah kelas yang cukup banyak tentunya dosen membutuhkan media pembelajaran yang efektif agar tujuan pembelajaran dapat tercapai.

Tujuan dari penelitian ini adalah (1) untuk mendeskripsikan penggunaan aplikasi Google dalam mata kuliah Pancasila, (2) untuk mengetahui kelebihan dan kekurangan dari aplikasi Google dalam pembelajaran online. Manfaat dari penelitian ini adalah dapat menambah pengetahuan dan keterampilan bagi tenaga pengajar dalam alternatif media pembelajaran online. Selain itu, menambah keaktifan mahasiswa dalam kegiatan pembelajaran online dengan menggunakan aplikasi Google.

\section{METODE}

Metode yang digunakan adalah kualitatif deskriptif. Subjek penelitian ini adalah 50 mahasiswa dan 3 dosen mata kuliah Pancasila prodi Teknik Informatika September- Desember 2020. Objek penelitian adalah aplikasi Google yang digunakan oleh dosen Pancasila. Teknik pengumpulan data adalah observasi, wawancara dan dokumentasi. Teknik analisis data yaitu reduksi data, penyajian data dan penarikan kesimpulan.

\section{HASIL DAN PEMBAHASAN}

Berdasarkan penggunaan aplikasi Google yang digunakan dalam mata kuliah Pancasila periode semester gasal 2020
/2021 bahwa dari 8 dosen pada mata kuliah Pancasila sebanyak 3 dosen menggunakan aplikasi Google dalam pembelajaran online yaitu penggunaan Google Classroom.

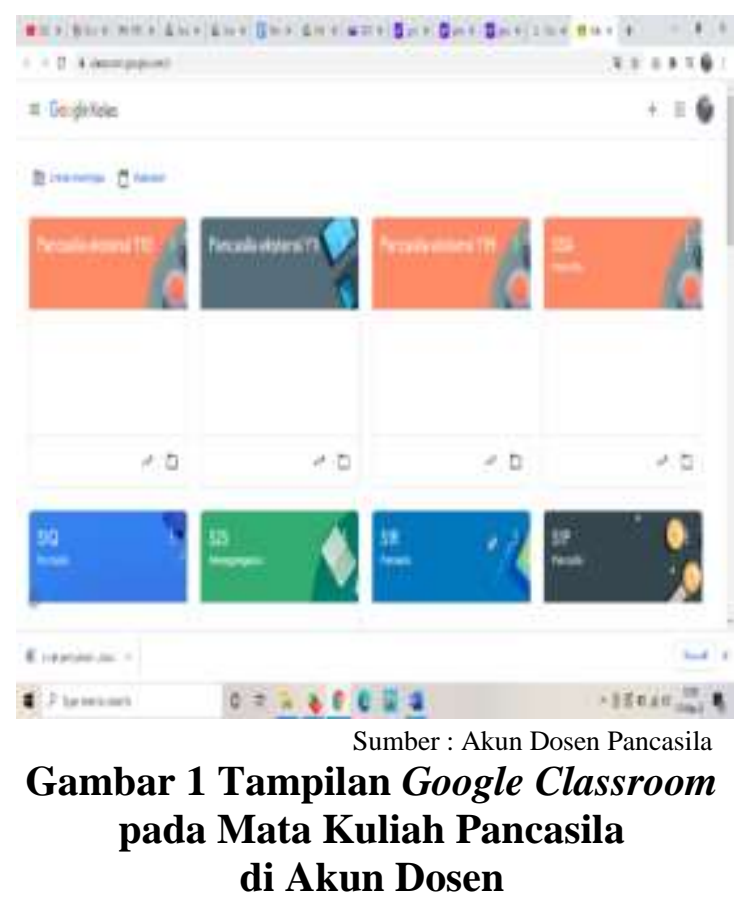

Salah satu aplikasi Google yang digunakan dalam mata kuliah Pancasila adalah Google Classroom. Melalui Google Classroom tentunya memudahkan dosen untuk melakukan pembagian materi, memberikan tugas, memberikan kuis, memberikan soal ujian, video serta semua mahasiswa dapat terawasi dalam classroom, sehingga memudahkan dosen dalam merekap segala administrasi pembelajaran pada kelas tersebut. Selain itu melalui Google Classroom, mahasiswa dapat memberikan komentar pada materi yang dibagikan maupun pada forum diskusi di classroom.

Melalui Google Classroom yang dapat diakses tanpa berbayar ke akun Google tentunya memberikan motivasi siswa dalam belajar lebih aktif dan meningkatkan kreativitas guru dalam pengajaran di tengah pandemi [10]. Melalui Google Classroom, pengajar dapat dengan bebas memberikan materi keilmuannya kepada 
mahasiswa tidak terbatas pada waktu serta memudahkan interaksi antara pengajar dengan siswa [6]. Melalui Google Classroom, pengajar dapat mengeksplor terkait segala hal yang menunjang dalam pembelajaran pada kelas online.

Dosen mata kuliah Pancasila menggunakan Google Classroom sangat membantu dalam pengajaran online terlebih dengan masing-masing dosen mengajar dengan lebih dari 10 kelas dapat memudahkan dosen dalam menyampaikan materi dan memberikan tugas melalui Google Classroom. Hanya saja dosen harus lebih berinovasi dan menarik minat mahasiswa dalam menyajikan materi agar tidak monoton, seperti dosen dapat memberikan video penjelasan yang dibagikan di classroom, sehingga mahasiswa dapat dengan langsung mengunduh video disertai dengan materi yang diberikan dosen.

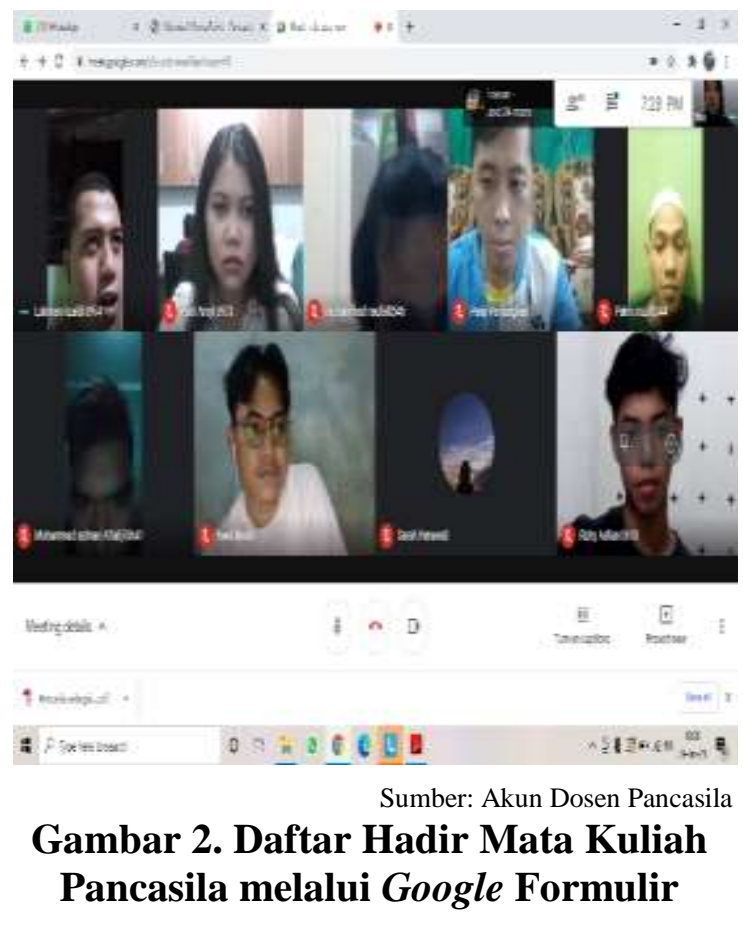

Aplikasi Google Formulir juga dijadikan beberapa dosen mata kuliah Pancasila untuk melakukan presensi setiap pertemuan maupun pengumpulan tugas. Melalui Google Formulir memudahkan dosen untuk merekap absensi maupun dalam mengumpulkan tugas.

Melalui Google Formulir tentunya memiliki banyak kelebihan antara lain pengguna dapat menentukan tema dan fitur yang unik disesuaikan dengan kebutuhan pengguna, adanya spread sheet yaitu memudahkan pengguna untuk mengetahui dengan cepat jawaban dari yang sudah diisi responden dan adanya menu kuis yang dapat diubah oleh pengguna terkait jenis soal yang akan dibagikan kepada responden [11]. Untuk Google Formulir, pada mata kuliah Pancasila, dosen lebih banyak digunakan untuk memberikan tugas maupun untuk absensi. Dengan jumlah rombel yang tiap dosennya dapat mengajar lebih dari 10 kelas tentunya Google Formulir ini memudahkan dalam merekap presensi pertemuan maupun memudahkan dalam penilaian tugas.

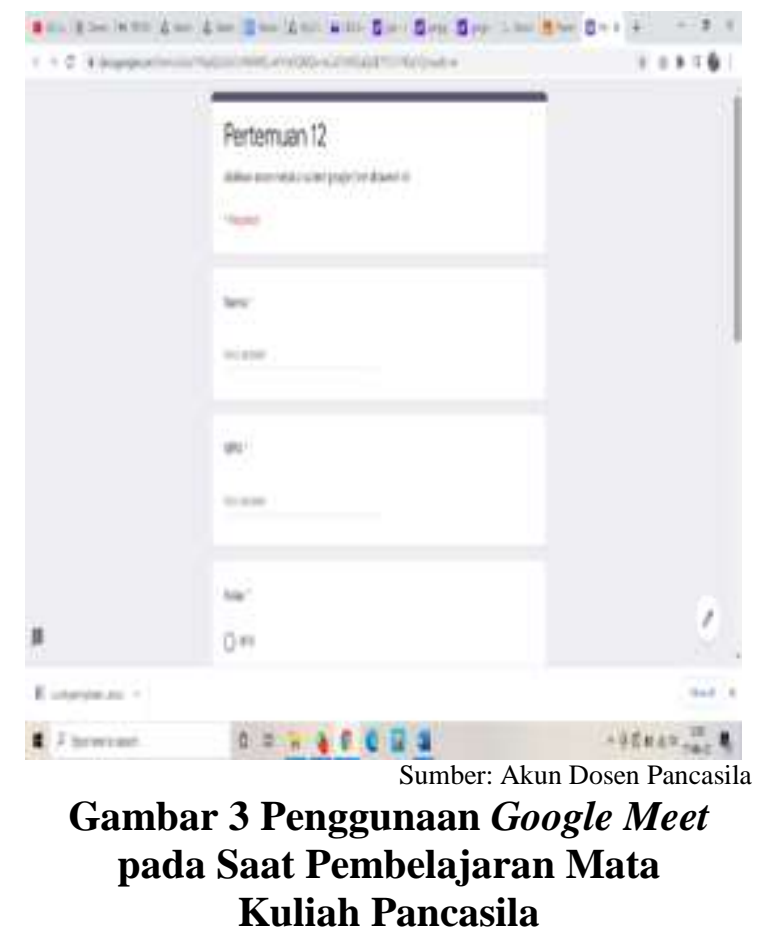

Google Meet adalah aplikasi Google yang sering digunakan oleh kebanyakan dosen mata kuliah Pancasila dalam pembelajaran. Tentunya hal ini dikarenakan melalui Google Meet dapat terjadi umpan balik 
yang cepat antar dosen dan mahasiswa secara virtual.

Di sisi lain, kekurangannya adalah banyak mahasiswa yang mematikan video pada saat google meeting, sehingga dibutuhkan kesabaran dan keterampilan dosen dalam pelaksanaan Google Meet berlangsung. Selain dapat berbicara langsung, melalui google meet dapat dibagikan materi pada saat dosen menjelaskan sehingga mahasiswa dapat mendengar suara dosen menjelaskan disertai tayangan power point yang disajikan dosen.

Dengan aplikasi Google Meet tentunya memudahkan dosen mata kuliah Pancasila dalam memberikan penjelasan materi kepada mahasiswa. Kemudahan yang disediakan dari aplikasi Google dapat dimanfaatkan dengan baik oleh beberapa dosen mata kuliah Pancasila.

Tentunya di tengah era digitalisasi, dosen dituntut dapat mengembangkan keterampilannya dalam pembelajaran secara daring. Mahasiswa pun dapat berinteraksi dengan dosen melalui ragam aplikasi Google yang dibutuhkan. Melalui aplikasi Google Classroom, Google Formulir dan Google Meet tentunya memiliki keunggulan masing-masing sesuai dengan kebutuhan pembelajaran online.

\section{Tabel 1. Kelebihan dan Kekurangan Aplikasi Google}

\begin{tabular}{|c|c|c|}
\hline No & Kelebihan Aplikasi Google & Kekurangan Aplikasi Google \\
\hline 1. & $\begin{array}{l}\text { Sangat mudah digunakan bagi } \\
\text { pemula yang menggunakan } \\
\text { pembelajaran online, mudah } \\
\text { mengelola tugas, gratis, bebas iklan } \\
\text { dan dosen mudah memberikan } \\
\text { informasi }\end{array}$ & $\begin{array}{l}\text { Jika google drive penuh maka } \\
\text { mahasiswa tidak dapat mengirimkan } \\
\text { file dan tampilan yang kurang menarik. }\end{array}$ \\
\hline 2 . & $\begin{array}{l}\text { Mudah digunakan, URL yang dapat } \\
\text { diperpendek, gratis dan dapat } \\
\text { mempermudah } \\
\text { pembelajaran. }\end{array}$ & $\begin{array}{l}\text { Design yang kurang menarik, tidak ada } \\
\text { riwayat modifikasi, Pilihan ekspor } \\
\text { terbatas pada pdf dan spread sheet, } \\
\text { serta tidak ada di pemberitahuan email. }\end{array}$ \\
\hline 3. & $\begin{array}{l}\text { Tersedia secara gratis, adanya white } \\
\text { board pada saat video konferensi dan } \\
\text { dapat dihadiri lebih dari } 30 \\
\text { partisipan. }\end{array}$ & $\begin{array}{l}\text { Jika ingin menambahkan fitur lainnya } \\
\text { maka harus berbayar serta dibutuhkan } \\
\text { jaringan internet yang stabil. }\end{array}$ \\
\hline
\end{tabular}

Penggunaan aplikasi Google seperti Google Classroom, Google Formulir dan Google Meet tentunya sangat memberi kemudahan dosen mata kuliah Pancasila dalam mengajar lebih dari 10 kelas yang dilakukan secara online. Hal ini tentunya menjadi sebuah inovasi dan peningkatan kreativitas serta keterampilan dosen, sehingga dituntut untuk senantiasa mampu menggunakan aplikasi yang menunjang pembelajaran online.

\section{SIMPULAN}

Berdasarkan hasil pengamatan selama pembelajaran mata kuliah Pancasila, wawancara dengan beberapa dosen Pancasila di Prodi Teknik Informatika serta dokumentasi yang digunakan dosen dalam penggunaan aplikasi Google, dapat ditarik simpulan bahwa dapat digambarkan aplikasi Google sebagai media pembelajaran pada mata kuliah Pancasila sangat bermanfaat bagi dosen mata kuliah Pancasila, sehingga memudahkan dosen dalam melakukan pengajaran kepada mahasiswa. Aplikasi Google yang dimanfaatkan oleh dosen Pancasila yaitu Google Classroom, Google Formulir dan Google Meet. Selain itu, kelebihan aplikasi Google sangat mudah dalam 
mengoperasikannya baik oleh dosen maupun mahasiswa. Aplikasi Google sangat bermanfaat dalam pembelajaran daring. Kekurangan pada ketiga aplikasi Google tersebut antara lain tampilan yang kurang menarik, jika ingin menambah fitur-fitur di Google harus berbayar tidak gratis serta jaringan internet harus stabil pada saat penggunaan aplikasi Google. Dengan keadaan seperti ini tentunya berharap agar aplikasi Google terus memberikan kemudahan bagi pengguna dengan memberikan fitur dan aplikasi yang lebih menunjang dan bermanfaat serta lebih menarik bagi pembelajaran online.

\section{DAFTAR PUSTAKA}

[1] T. Tafonao, "Peranan Media Pembelajaran dalam Meningkatkan Minat Belajar Mahasiswa," $J$. Komun. Pendidik., vol. 2, no. 2, pp. 103-109, 2018, doi: 10.32585/jkp.v2i2.113.

[2] N. Septantiningtyas, "Pengaruh Pembelajaran Jarak Jauh dengan Aplikasi Google Class terhadap Hasil Belajar Mahasiswa," Edureligia; J. Pendidik. Agama Islam, vol. 2, no. 2, pp. 131-135, 2018, doi: 10.33650/edureligia.v2i2.714.

[3] Y. Hidayah, N. Ulfah dan Suyitno, "Analisis Pendekatan Pembelajaran Mata Kuliah Wajib Umum Pancasila dan Pendidikan Kewarganegaraan di Perguruan Tinggi," J. Pancasila Dan Kewarganegaraan, vol. 4, no. 1, pp. 22-33, 2019, doi: 10.24269/jpk.v4.n1.2019.pp22-33.

[4] S. Bulan dan H. S. Zainiyati, "Pembelajaran Online Berbasis Media Google Formulir dalam Tanggap Work From Home Masa Pandemi Covid-19 di Madrasah Ibtidaiyah Negeri (MIN) 1 Paser," SYAMIL J. Pendidik. Agama Islam
(Journal Islam. Educ.), vol. 8, no. 1, pp. 15-34, Jun. 2020, doi: 10.21093/sy.v8i1.2300.

[5] U. Rahardja, N. Lutfiani, dan M. S. Alpansuri, "Pemanfaatan Google Formulir sebagai Sistem Pendaftaran Anggota pada Website Aptisi.or.id," Sisfotenika, vol. 8, no. 2, p. 128, 2018, doi: 10.30700/jst.v8i2.401.

[6] N. Fauziyah, "Dampak Covid-19 terhadap Efektivitas Pembelajaran Daring Pendidikan Islam," Jurnal AlMau'izhoh, vol. 2. no. 2, pp. 1-11, 2020.

[7] P. A. Umum, "Google Classroom sebagai Solusi Pembelajaran Jarak Jauh Mata Pelajaran Administrasi Umum," Indonesian Journal of Education and Learning, vol. 4, no. 2, pp. 456-461, doi: 10.31002/ijel.v4i2.3111.

[8] I. Aripin, "Mobile Learning Sebuah Aplikasi Teknologi Pembelajaran Biologi," Bio Educ., vol. 3, no. 1, pp. 01-09, 2018.

[9] Suharno, "Urgensi Revitalisasi Pancasila dalam Membangun Karakter Kebangsaan," Jurnal Pancasila dan Kewarganegaraan, vol. 2, no. 1, pp. 23-33, 2017, doi: 10.24269/jpk.v5.n1.2020.

[10] Sutrisno, "Peningkatan Aktivitas dan Hasil Belajar Melalui Pembelajaran Online dengan Google Classroom di Masa Pandemi Covid 19," Jurnal Karya Ilmiah Guru, vol. 5, no.1, pp. 95-100, 2020.

[11] R. M. Yusron, R. Wijayanti, dan A. T. Novitasari, "Pelatihan Pembuatan Google Form bagi Guru SD sebagai Media Evaluasi Pembelajaran Jarak Jauh (PJJ) Masa Pandemi," Publ. Pendidik., vol. 10, no. 3, p. 182-188, 2020 , doi: 10.26858/publikan.v10i3.15055. 